\title{
ROMPER BINÁRIOS DE GÊNERO E SEXUALIDADE: ENSAIAR UMA EDUCAÇÃO NÃO-BINÁRIA
}

\author{
Roney Polato de CASTRO ${ }^{1}$ \\ Universidade Federal de Juiz de Fora (UFJF) \\ roneypolato@gmail.com \\ Neilton dos REIS ${ }^{2}$ \\ Universidade Federal de Juiz de Fora \\ neilton.dreis@gmail.com
}

Resumo: O texto ensaia possibilidades de pensar a educação escolar e a formação docente como instâncias de produção de significados sobre os gêneros e as sexualidades, buscando problematizar um pressuposto: as oposições binárias. De que modos os processos educativos-formativos produzem e reforçam binarismos de gênero e sexualidades? Quais os efeitos do pensamento binário e de que modos os currículos e as práticas escolares se organizam a partir dele? Poderíamos ensaiar pensamentos não-binários em educação? Suspeitamos de que os binarismos produzem e reforçam relações de poder que enquadram e hierarquizam sujeitos e práticas. Dialogando com teorizações e estudos contemporâneos, tomamos a educação como campo de produção de experiências, tendo como referência o pensamento queer e os estudos pós-críticos como mote para pensar outras práticas, rompendo fronteiras, suspeitando de verdades embasadas em campos discursivos como as ciências biológicas e as religiões, pluralizando processos identitários.

Palavras-chave: educação; pensamento não-binário; gêneros; sexualidades; pensamento queer.

\begin{abstract}
The text rehearses possibilities for thinking school education and teaching formation as instances of production of meanings about genders and sexualities searching to problematize an assumption: binary oppositions. What modes do educational-formative processes produce and strengthen binarisms of gender and sexualities? What are the effects of binary thought and how curriculum and school practices are organized from it? Could we rehearse non-binary thoughts in education? We suspect that binarisms produce and strengthens power relations that frame and hierarchize subjects and practices. Arguing with theorizations and contemporary studies we take education as a field of experience production, with reference to queer thoughts and post-critical studies as a motto for thinking about other practices, breaking boundaries, suspecting truths based on discursive fields such as biological sciences and religion, pluralizing identity processes.
\end{abstract}

Keywords: education; non-binary thought; genders; sexualities; queer thought.

\footnotetext{
1 Professor do Departamento de Educação e do Programa de Pós-Graduação em Educação da Universidade Federal de Juiz de Fora (UFJF). Integra o GESED - grupo de estudos e pesquisas em Gênero, Sexualidade, Educação e Diversidade.

2 Licenciado em Ciências Biológicas (UFRRJ) e Mestrando em Educação pelo Programa de Pós-graduação em Educação da Universidade Federal de Juiz de Fora (UFJF). Integra o GESED - grupo de estudos e pesquisas em Gênero, Sexualidade, Educação e Diversidade.
} 


\section{Canção}

(Federico García Lorca)

Pelos ramos do loureiro

vão duas pombas escuras.

Uma era o sol,

a outra, a lua.

Vizinhas, disse-lhes,

onde está minha sepultura?

Em minha cauda, disse o sol.

Em minha garganta, disse a lua.

E eu que estava caminhando

com terra pela cintura

vi duas águias de mármore

e uma rapariga desnuda.

Uma era a outra

e a rapariga era nenhuma.

Aguiazinhas, disse-lhes,

onde está minha sepultura?

Em minha cauda, disse o sol.

Em minha garganta, disse a lua.

Pelos ramos da cerejeira

vi duas pombas desnudas

uma era a outra,

e as duas eram nenhuma.

Apropriamo-nos do jogo das metáforas do imaginário de García Lorca, pois sua poesia transgride, sutilmente, uma das lógicas que organiza a metafísica ocidental: o pensamento organizado em binários oposicionais. As pombas do poeta se ligam em cauda e garganta, ambas berço da sepultura do caminhante (o que se põe em movimento). Esse, que transita em seus questionamentos, tem sua sepultura estabelecida, ao que parece, no determinismo de um binário: a noite ou o dia. Porém, a cauda do dia mantém uma relação íntima com a garganta da noite, tão íntima que se mistura e enlaça um mesmo fim sepulcral. Águias e pombas se confundem, bem como dia e noite, a tal ponto que uma era outra, e as duas eram nenhuma. Ser tão si, quanto o outro. Não ser coisa alguma. Ser muitas coisas. As desterritorializações das identidades são a rapariga desnuda, a sepultura, as aves que se estendem pelos ramos de loureiro e cerejeira do tempo.

É no âmbito das simplicidades das experiências que escapam da noite e do dia, mas que se fundem entre a cauda de uma e a garganta de outra, que este trabalho se movimenta. 
É a dúvida do lugar (ou não-lugar) da sepultura que motiva o caminhar desse texto. Para tal, é necessário imergir nessas metáforas, compreendê-las e então potencializá-las para se debruçar sobre as desconstruções dos binarismos, a construção da diferença e da nãobinaridade.

Este texto parte de estudos e pesquisas em educação que se aliam às perspectivas pós-críticas para pensar e ensaiar discussões em torno das relações de gêneros e sexualidades. Educação, gêneros, sexualidades como constitutivos de sujeitos e subjetividades, atravessados pela linguagem, pelo poder, pela cultura. Ensaiar possibilidades de pensar processos pedagógicos não-binários na educação que produz sujeitos de gêneros e de sexualidades. Sentimo-nos inquietados com as potencialidades que os estudos pós-críticos anunciam para pensar a educação escolar e as lógicas binárias que a organizam. Se tal organização dualista e oposicional é uma herança ocidental (BUTLER, 2003; HERMANN, 2014; DERRIDA, 2001), espera-se que ela se inscreva por entre e através de todas as instituições, discursos, dispositivos que se construíram no ocidente. Assim, pensar os binarismos da/na escola não poderia se resumir a pensá-los apenas na perspectiva dos gêneros e sexualidades.

Este texto também se configura pelas provocações de uma pesquisa de mestrado em construção, que investe na potencialidade de encontrar com sujeitos que se autoidentificam como não-binários no que diz respeito às suas expressões e performances de gênero. Foram três os sujeitos que encontramos e que conversamos em dois encontros individuais com cada um. Para o primeiro encontro discutimos as linhas de fuga da nãobinaridade que permeiam as questões de gênero; para o segundo, nos debruçamos sobre os currículos (escolares e não-escolares) que foram ao/de encontro com as experiências não-binárias. São narrativas dos segundos encontros que trazemos para essa argumentação. Assim, perpassamos por algumas imersões no 'chão da escola' - com terra pela cintura - através das narrativas dessas pessoas que ali caminham ou caminharam. Interessa-nos problematizar identidades que se colocam como a rapariga desnuda, de local sepulcral, de dia e noite que se enlaçam. Para tal, (re)corremos ao campo teórico dos estudos pós-críticos que têm lançado mão das desnaturalizações dos binários que constituem os sujeitos.

Com Jacques Derrida (2001), no diálogo que constrói em Posições, nos atentamos aos perigos de encarar dia e noite como pares que não se inserem em um sistema de significação e violências. Assim, e seguindo uma perspectiva foucaultiana de produção 
que se propõe experiência, investimos em pistas sobre a constituição dos binarismos e seus perigos na educação e ensaiamos pensar espaços que a escola tem costumado ignorar, silenciando-os. Os lugares que apontamos são aqueles que estão entre a sala de aula e os muros da escola - que são escola, mas não são aula; que estão entre as experiências do aprendizado "científico e legitimado" e as "badernas" - que são currículo, mas constantemente deslegitimados; estão entre os/as docentes "experientes e portadores da verdade" e os/as discentes "imaturos e inocentes"; entre a segurança e clareza do dia e os perigos e obscuridades da noite.

\section{Problematizando binarismos na educação}

Jacques Derrida (2001), em entrevista a Jean-Louis Houdebine e Guy Scarpetta, retoma algumas de suas ideias e as confronta entre si e com outros pensadores, principalmente Hegel. Durante todo o texto, a discussão da differance é bem marcada e os olhares para os binarismos são advogados para que não se perca o foco de enxergá-los como um sistema de violência, de forma que exista uma fase de inversão, que permita (re)pensar os papeis de opressores e oprimidos que estão sendo constantemente produzidos.

Insisto muito e incessantemente na necessidade dessa fase de inversão que se pode, talvez, muito rapidamente, buscar desacreditar. Fazer justiça a essa necessidade significa reconhecer que, em uma oposição filosófica clássica, nós não estamos lidando com uma coexistência pacífica de um face a face, mas com uma hierarquia violenta. Um dos dois termos comanda (axiologicamente, logicamente etc.), ocupa o lugar mais alto. Desconstruir a oposição significa, primeiramente, em um momento dado, inverter a hierarquia. Descuidar-se dessa fase de inversão significa esquecer a estrutura conflitiva e subordinante da oposição. Significa, pois, passar muito rapidamente - sem manter qualquer controle sobre a oposição anterior - a uma neutralização que, praticamente, deixaria intacto o campo anterior, privando-se de todos os meios de aí intervir efetivamente. Sabe-se quais tem sido, sempre, os efeitos práticos (em particular, políticos) de passagens que saltam imediatamente para além das oposições, bem como das constatações feitas do simples nem isso/nem aquilo. (DERRIDA, 2001, p. 48, grifos do autor).

Estabelecer binários é, portanto, uma operação de poder. Os termos dessas oposições não são simplesmente dispostos numa simetria, ao contrário, tais oposições 
carregam consigo assimetrias que implicam hierarquias. Silvia Duschatzky e Carlos Skliar (2011) associam a invenção das lógicas binárias à produção de "componentes negativos" das relações culturais: "marginal, indigente, louco, deficiente, drogadinho, homossexual, estrangeiro etc.”, ou seja, as oposições binárias inventadas pela Modernidade "sugerem sempre o privilégio do primeiro termo e o outro, secundário nessa dependência hierárquica, não existe fora do primeiro, mas dentro dele, como imagem velada, como sua inversão negativa" (p. 123). Tal como Derrida (2001) nos provoca: não se trata de uma coexistência pacífica, mas de uma hierarquia violenta, já que produz subordinações e reitera noções de normalidade e ordenamento. Assim, a desconstrução implica em visibilizar os modos como se dão os processos de atribuição das diferenças como operações de poder.

Guacira Louro (2003) explicita as proposições de Derrida sobre o pensamento moderno, marcado pelo "jogo das dicotomias", no qual dois pólos diferem e se opõem, como se cada um fosse uno, homogêneo, idêntico a si mesmo. Além disso, a lógica dicotômica marca uma pretensa superioridade do primeiro termo, produzindo as hierarquias. A proposta de desconstrução das dicotomias implicaria na problematização da constituição de cada pólo, “demonstrando que cada um na verdade supõe e contém o outro, evidenciando que cada pólo não é uno, mas plural, mostrando que cada pólo é, internamente, fraturado e dividido" (p. 31). Como argumenta a autora, essa pode se constituir numa estratégia subversiva e fértil para o pensamento, já que a desconstrução "faz perceber que a oposição é construída e não inerente e fixa. A desconstrução sugere que se busquem os processos e as condições que estabeleceram os termos da polaridade. Supõe que se historicize a polaridade e a hierarquia nela implícita.” (p. 32).

Duschatzky e Skliar (2011) chamam a atenção para a lógica binária como relação, ou seja, o "outro" termo aponta para as ansiedades, contradições e irracionalidades do primeiro, portanto, "representa aquilo que é profundamente familiar ao centro, porém, projetado para fora de si mesmo" (p. 123). Portanto, o "outro" é necessário como forma de justificar o que somos, nossas leis, instituições, regras, discursos e práticas. O "outro" é necessário para que se possa "nomear a barbárie, a heresia, a mendicidade etc. e para não sermos, nós mesmos, bárbaros, hereges, mendigos" (p. 124). Essa lógica habita o campo da educação, povoado de oposições entre, de um lado, o desejável e legítimo, e de outro, o ilegítimo. Como argumenta Najda Hermann 
(2014), ao apontar uma perspectiva questionadora das potencialidades do espaço educacional para ampliar as discussões em torno do convívio entre as diferenças:

\begin{abstract}
Profundamente influenciada pelos dualismos presentes nessa herança [da metafísica ocidental], tais como corpo e alma, civilização e barbárie, razão e desrazão, a educação tende a ver o outro como tudo o que se opõe às idealizações: o bárbaro, o selvagem, o infiel. Transpõe, tanto para o cotidiano como para o âmbito das especialidades científicas e também para o âmbito cultural, o peso interpretativo dessas oposições e identifica o educando como o desviado, o desadaptado, o desobediente, o hiperativo etc. (HERMANN 2014, p. 479).
\end{abstract}

Seguindo o que propõe Hermann (2014), a apropriação das ideias de Derrida para a educação implica analisar esse campo e a própria "teoria educacional" como lugar dos binarismos caros à tradição do pensamento filosófico ocidental: libertação/opressão, teoria/prática, racional/irracional, saber/ignorância entre tantos outros. Assim, quando dirigimos nossa atenção para a escola, entendemos que ao instituir alguns sujeitos como propriamente detentores do saber e da verdade (comumente docentes), ela constituiria outros sujeitos como incapacitados (discentes); ao instituir um ambiente próprio para o aprendizado (comumente a sala de aula), ela instituiria tantos outros como nulos e impróprios (fora das salas e fora dos muros da escola); ao instituir uma ordem, ela enquadra e classifica os/as desajustados/as e desobedientes; ao privilegiar as experiências previstas em seus planejamentos, currículos, pedagogias, ela pode conferir inutilidade àquelas que não foram antes classificadas como relevantes.

Tomemos a oposição adequado/inadequado para questionar a construção de currículos e saberes escolares 'disciplinados' ou 'disciplinarizados'. Em conversas com professoras de Ciências e Biologia, estudantes da Educação Básica e a partir de narrativas de estudantes de licenciatura em experiências de estágios nas escolas, ouvimos críticas e desconfortos em relação a certos saberes que chegam às salas de aula, no que se refere aos desejos, prazeres e práticas sexuais. O saber das experiências sexuais, prazerosas ou não, aqueles que se produzem com os artefatos culturais, especialmente filmes pornôs e imagens que circulam pelos celulares e pelos demais aparelhos com acesso à Internet, são encarados como um saber 'sujo'(para operar com palavras das/os próprias/os estudantes), um saber aparentemente inválido para a sala de aula e para um currículo escolar. Nas práticas intituladas de "educação sexual", os saberes das experiências de estudantes nãoheterossexuais são, frequentemente, silenciados, pois poderiam 'despertar' outras/os 
estudantes para práticas, desejos e prazeres 'inadequados'. Entre experiências e saberes higienizados e adequados ou sujos e inadequados, as oposições instauram hierarquias entre saberes, sujeitos, subjetividades, gêneros e sexualidades.

A oposição entre 'saberes sujos e limpos' nos interessa também para pensar em outro exemplo. Não é raro ouvir de opositoras/es à inclusão das abordagens de gênero e sexualidade nas escolas que "estão querendo ensinar estudantes a transar". A partir do campo dos estudos de gênero, sexualidade e educação, nosso argumento é que os objetivos dessas abordagens não incluem tal ensinamento. Certamente outras instâncias se encarregarão dele e a escola poderá, talvez, problematizá-los. Queremos pensar nesse entendimento de que os saberes sobre as relações sexuais (para além dos 'coitos reprodutivos' presentes nos enunciados de 'educação sexual') não são válidos para o contexto escolar. Os saberes escolares, transpostos e refeitos a partir dos conhecimentos historicamente 'acumulados', vêm sendo, com esses processos, selecionados, disciplinados e hierarquizados: existiriam saberes 'limpos', adequados para a sala de aula, e saberes 'sujos', que devem habitar outros contextos, fora do ordenamento escolar, apesar de insistirem em se fazer presentes. Para Julia Varela (2010), a instituição de "saberes disciplinares e disciplinarização dos sujeitos são as duas faces de um processo que atravessa o conjunto da organização escolar” (p. 94). Nesse sentido, além da produção de um binário que permite ou recusa saberes (e também os transforma para torná-los 'aceitáveis'), são produzidos, na mesma lógica, sujeitos adequados e inadequados. Porém, tal oposição não teria como objetivo impedir a existência dos saberes 'outros' - 'sujos', 'inadequados', pois estes são necessários para que os 'limpos' reafirmem-se como tal. Lembrando Duschatzky e Skliar (2011), os “outros" são fundamentais para que a normalidade e a ordem se estabeleçam, para que se possa justificá-las.

Considerando as oposições binárias que habitam as escolas, produzindo hierarquias e subalternizando sujeitos e saberes, sustentadas por jogos de poder - incluir/excluir, educar/vigiar/disciplinar/punir - nossas análises vão ao encontro do que dizem Roger Deacon e Ben Parker (2010): “a generalização da normalização opera através da criação de anormalidades que ela [a educação], então, deve tratar e reformar" (p. 105). Assim, os mecanismos institucionalizados da escola, organizados com uma lógica binária, podem produzir espaços e sujeitos incapacitados, inadequados e insignificantes, justificando violências. A partir desses argumentos, nos voltamos para pensar os binarismos que organizam, especificamente, a constituição dos gêneros e das sexualidades. 


\section{Problematizando binarismos de gênero e sexualidade}

Os binários de gênero e sexualidade vêm, historicamente, organizando os modos de pensar o lugar dos sujeitos nas sociedades ocidentais. Masculino ou feminino, homem ou mulher, heterossexual ou homossexual são oposições que embasam muitos dos modos de pensar os sujeitos, as instituições, as políticas e práticas socioculturais. Como argumenta Berenice Bento (2008), a vinculação dos comportamentos ao sexo e do gênero às genitálias, ou seja, o feminino definido pela presença de vagina e o masculino pelo pênis, remonta ao século XIX.

O sistema binário (masculino versus feminino) produz e reproduz a ideia de que o gênero reflete, espelha o sexo e que todas as outras esferas constitutivas do sujeito estão amarradas a essa determinação inicial: a natureza constrói a sexualidade e posiciona os corpos de acordo com as supostas disposições naturais. (BENTO, 2008, p. 17).

Até meados do século XVII, imperava uma interpretação isomórfica sobre os corpos, ou seja, existiria apenas um corpo (uma anatomia) e dois gêneros. Até então, as diferenças anatômicas e fisiológicas visíveis entre os sexos não eram politicamente importantes. A ascensão dos discursos científicos nos séculos XVIII e XIX contribuirá sobremaneira para que as diferenças biológicas entre homens e mulheres se tornem fundamentais para explicar a ordem moral e social. Se no isomorfismo a mulher era "um homem invertido", a partir do século XIX passa a vigorar uma discursividade dimórfica: estabelecidas as distinções anatômicas e fisiológicas entre homens e mulheres, a organização social deveria, assim, "ser ditada e orientada pela natureza. Nada se poderia fazer contra o império da natureza a não ser render-se a ela.” (BENTO, 2008, p. 31). A naturalização do sexo como fundamento das desigualdades sociais será questionada pelos estudos feministas a partir de meados dos anos de 1970. Era preciso demonstrar, como aponta Guacira Louro (2003),

que não são propriamente as características sexuais, mas é a forma como essas características são representadas ou valorizadas, aquilo que se diz ou se pensa sobre elas que vai constituir, efetivamente, o que é feminino ou masculino em uma dada sociedade e em um dado momento histórico. Para que se compreenda o lugar e as relações de homens e 
mulheres numa sociedade importa observar não exatamente seus sexos, mas sim tudo o que socialmente se construiu sobre os sexos. (p. 21).

Nesse contexto, o conceito de gênero surge como forma de rejeitar o determinismo biológico implícito nos termos sexo e diferença sexual. Pretendia-se, como argumenta Louro (2003), enfatizar "a construção social e histórica produzida sobre as características biológicas.” (p. 22). No entanto, com a compreensão de que o gênero diz dos significados culturais assumidos pelo corpo sexuado, as proposições feministas produzirão outra distinção: sexo/gênero. Como analisa Judith Butler (2003), tal distinção sugere "uma descontinuidade radical entre corpos sexuados e gêneros culturalmente construídos." (p. 24). Desse modo, investe-se na oposição entre sexo como elemento da natureza, algo aparentemente não problemático, e gênero como elemento da cultura. Butler (2003) nos convida à discussão, investindo na ideia de que essa oposição encerra a crença de que o gênero reflete o sexo. Para a autora, o sexo é tão culturalmente construído quanto o gênero: "a rigor, talvez o sexo sempre tenha sido o gênero, de tal forma que a distinção entre sexo e gênero revela-se absolutamente nenhuma." (p. 25).

Berenice Bento (2014) chama a atenção para o fato de que, inicialmente, os estudos de gênero operavam a partir de uma perspectiva oposicional/binária, tomando a condição biológica como universal, na qual o corpo é pensado "como uma folha em branco, esperando o carimbo da cultura" (p. 83). Posteriormente, ao longo da década de 1990, outros estudos apontaram para uma perspectiva relacional, a partir da qual masculino e feminino se constroem relacionalmente, não em oposição. Embora aponte para uma relação, esses estudos ainda mantém um pensamento, de certo modo, binário para os gêneros sexualidades. Com isso, as multiplicidades podem ser invisibilizadas e os sujeitos que não se enquadram nas formas dicotômicas são ignorados ou negados. Sobretudo, romper as dicotomias de gênero poderá, como propõe Louro (2003), abalar o "caráter heterossexual" enraizado no conceito de gênero.

Joan Scott (1995), em suas análises sobre a formulação do conceito de gênero, convida-nos a uma rejeição do caráter fixo e permanente da oposição binária que caracteriza os termos da dicotomia masculino-feminino. Utilizando a definição de desconstrução de Jacques Derrida, a historiadora norte-americana propõe analisar as formas pelas quais essas oposições binárias operam, de modo a reverter e deslocar as construções hierárquicas estabelecidas. Como argumenta Louro (2003), Scott e outras estudiosas feministas ligadas às teorizações pós-críticas, observam que as sociedades se 
organizam a partir de um pensamento dicotômico e polarizado sobre os gêneros, concebendo homem e mulher como pólos que se relacionam numa lógica de dominação/submissão. A desconstrução da polaridade rígida dos gêneros implicaria observar

que o pólo masculino contém o feminino (de modo desviado, postergado, reprimido) e vice-versa; implicaria também perceber que cada um desses pólos é internamente fragmentado e dividido (afinal não existe $a$ mulher, mas várias e diferentes mulheres que não são idênticas entre si, que podem ou não ser solidárias, cúmplices ou opositoras). (LOURO, 2003, p. 32).

Mais recentemente, os estudos de gênero e sexualidade incorporaram a perspectiva de analíticas queer, a partir da ideia do múltiplo, da desnaturalização e da legitimidade das "sexualidades divergentes" (BENTO, 2014, p. 95). A política queer coloca-se contra a normalização, opõe-se à heteronormatividade e subverte as políticas identitárias. $\mathrm{O}$ queer, como aponta Guacira Louro (2004), relaciona-se ao estranhamento, à contestação, ao que está fora do centro. Certamente, os binários serão alvo dessa política subversiva, entre elas a oposição binária heterossexual/homossexual, responsável pela reiteração de hierarquias e exclusão das multiplicidades, "compreendida como a categoria central que organiza as práticas sociais, o conhecimento e as relações entre os sujeitos.” (p. 46).

As analíticas queer também recairão sobre a distinção sexo/gênero e sobre a premissa que impõe um sexo determinando um gênero, que por sua vez induz a uma forma de desejo. Essa sequência afirma e repete uma norma, "apostando numa lógica binária pela qual o corpo, identificado como macho ou fêmea, determina o gênero (um de dois gêneros possíveis: masculino ou feminino) e leva a uma forma de desejo (especificamente, o desejo dirigido ao sexo/gênero oposto)." (p. 80). Sob a ótica queer, essa sequência, tida como natural e incontestável, pode ser subvertida, desviada, desafiada. Há investimentos sutis e continuados para que ela funcione, desde os primeiros momentos da existência. Como argumenta Louro (2004) a afirmação "é um menino" ou "é uma menina" inaugura um processo de masculinização ou de feminilização, algo como um "trabalho pedagógico contínuo, repetitivo e interminável", que "é posto em ação para inscrever nos corpos o gênero e a sexualidade 'legítimos'." (p. 16).

Ao problematizar a sequência sexo-gênero-sexualidade, os estudos queer atentamse para as experiências de abjeção produzidas quando os sujeitos escapam da norma cis- 
heterossexual, provocando descontinuidades e brechas e, portanto, constituindo-se como uma ameaça à ordem social e política. Porém, mesmo considerados estranhos ou anormais, os sujeitos marginalizados continuam necessários para delimitar a centralidade da norma. A lógica binária que sustenta essa ordem torna impensáveis as multiplicidades sexuais e de gêneros. "O queer, portanto, [...] é a recusa dos valores morais violentos que instituem e fazem valer a linha de abjeção, essa fronteira rígida entre os que são socialmente aceitos e os que são relegados à humilhação e ao desprezo coletivo" (MISKOLCI, 2012, p. 25).

É a partir da perspectiva queer que escolhemos nos debruçar sobre as narrativas escolares que dizem das diferenças ao binário de gênero. Apostamos que as desestabilizações que essas narrativas podem produzir no 'chão da escola' indicam um movimento de experienciar a política queer. As hierarquias constituídas pela lógica binária parecem se diluir em multiplicidades e em jogos de poder, imbricadas em negociações de prazer e de desconforto. (Re)pensar as construções de gênero e sexualidade nos espaços escolares, nessa perspectiva, pode ser colocar em suspensão todas as práticas que vêm (re)construindo qualquer binarismo.

\section{Pensando as (não)binaridades de gênero e sexualidade na escola}

Muitos dos espaços e práticas escolares, como já sinalizados, apontam para uma matriz de normas de gênero binária: na separação de banheiros, na organização de estudantes (especialmente nas séries iniciais) em filas, em alguns momentos da disciplina de Educação Física, a distribuição de brinquedos, entre outros exemplos, podemos observar a construção das identidades femininas ou masculinas. Em outras palavras, é também na escola que aprenderemos a ser mulher ou ser homem. Nesse sentido, acreditamos que pensar as linhas de fuga na não-binaridade de gênero e sexualidade dentro da escola pode ser um caminhar em direção à transgressão da lógica ocidental dentro de uma das instituições que mais a reforça.

Neste momento, tomaremos as narrativas que pessoas autoidentificada como nãobinárias em relação aos gêneros para pensar essa construções escolares. Nenhuma das pessoas que narraram suas experiências no âmbito da pesquisa frequentou a escola tendo como identificação a não-binaridade de gênero. Entretanto, o processo de diferenciação e desconforto com o binário de gênero já eram sentidos, bem como alguns rompimentos 
com a heteronormatividade. As narrativas de Irene e Nicholas ${ }^{3}$ indicam algumas pistas para pensar a escola em contato com as temáticas de sexualidade e de gênero e, ainda, as desestabilizações quando essa temática diz da diferença ao binário.

Nicholas: Esses temas apareciam, mas não sentia que era algo relevante. Algo que mudasse o relacionamento com as pessoas. Aquela escola era maravilhosa pra você se assumir. Ninguém virava e apontava e "ah, viadinho", sabe? Todo mundo respeitava e continuava conversando contigo da mesma forma. Pelo menos na minha série era assim. Não tinha caso de pessoas trans. Mas eu imagino que seria mais de boas que em outras escolas. Tinha muita lésbica, muito gay e muito bi. Era uma escola maravilhosa. Não era falado, a gente não falava muito sobre, porque parecia que naquela escola todos eram iguais, sabe?! Era um lugar tranquilo. Aula nunca teve. De sexualidade, não. De gênero, também não. Biologia vira e fala: "pepeca e pipi”. E só isso. Não tinha essa coisa de identidade de gênero. Não, nunca foi falado.

Pesquisador: E como você acha que seria se tivesse uma pessoa não-binária na sua escola?

Nicholas: Eu acho que todo mundo ia ficar muito curioso. Querendo saber o que é. Tem gente que ia achar estranho. Tem gente que ia fazer umas perguntas bestas. Mas, eu acho que ia trazer muita curiosidade. Pra saber o que é, porque não se sabe.

Pesquisador: E como você acha que a instituição ia lidar?

Nicholas: Ah, ia ignorar. Como sempre ignorou. Lá era de boas por causa dos alunos, porque a instituição nunca fez nada.

A narrativa de Nicholas não aponta para transgressões à matriz binária de gênero e sexualidade, ainda que a escola lhe tenha sido um lugar confortável. As aulas de Biologia se fazem exemplos recorrentes para dizer tanto da forma que as temáticas de corpo, gênero e sexualidade estão geralmente dispostas no currículo programado para a sala de aula, quanto da perspectiva de trabalho: "pepeca e pipi”. De acordo com Lorenzo Bernini (2011, p. 19), essa forma binária de pensar o gênero tem raízes no determinismo da ciência moderna, na qual variações da estrutura sexual macho ou fêmea são tidas como existências “contranatureza". Para ele, essas existências são estabelecidas como desviantes. Assim, o sentimento de Nicholas que a não-binaridade de gênero naquele espaço escolar poderia provocar estranheza e curiosidade parece estar associado ao sentimento do ser desviante, exótico e potencialmente abjeto - aquilo que "incomoda a

\footnotetext{
${ }^{3}$ Nomes fictícios escolhidos pelas próprias pessoas no momento dos encontros. MARGENS - Revista Interdisciplinar

Dossiê: Corpo, Gênero e Sexualidade Versão Digital - ISSN: 1982-5374 VOL.11. N. 17. Dez 2017. (p. 108-124)
} 
ordem [binária], coloca em xeque sua aspiração à pureza e, portanto, a ameaça com os contatos e as trocas" (MISKOLCI, 2014, p. 23).

Outro ponto a pensar é que Nicholas indica para uma experiência de prazer dentro da escola. Tal experiência é associada ao comportamento de estudantes frente às diferenças sexuais. Rita Radl-Philipp (2014, p. 52) lança olhar a esse ponto chamando à atenção para o papel das alunas e alunos nas ações educativas. Pensamos ser injusto e incoerente pensar esses indivíduos como sujeitos passivos, que apenas incorporam conceitos rígidos e pré-estabelecidos. Eles, ao contrário, constituem a socialização escolar ativamente, interferindo na sua dinâmica e dando formatos novos e característicos para aquela geração. As atividades desenvolvidas por eles poderão manter padrões antigos sem o questionamento de relações de poder, por exemplo, ou assumir outros significados e significantes. Parece ser o que indica Nicholas quando aponta que "Ninguém virava e apontava e "ah, viadinho", sabe?". As violências normalizadas contra a população LGBTTI parecem estar sendo ressignificadas naquele contexto.

No que concerne ao gênero, as alunas e os alunos reproduzem o esquema binário, mas também podem completá-lo ou ressignificá-lo. Lorenzo Bernini (2011, p. 20) vai explorar essa ressignificação apontando que gêneros e sexualidades marginalizados têm forçado a entrada no sistema educacional, rompendo com os binarismos. Essas ações podem ter a potência de abalar o sistema repressivo que impõe uma matriz heteronormativa. É o que traz, também, a narrativa de Irene:

Irene: Depois que eu me assumi eu passei a conversar muito. As pessoas, minhas amigas, sempre perguntavam as coisas, a gente debatia. Antes disso, não. Raramente. Porque o ensino hoje tem uma deficiência muito grande em abordar esses temas. Então, os sistemas acabam virando tabus e as pessoas acabam ficando ressentidas e intimidadas a tocar nesse assunto.

[...]

Depois que eu me assumi, eu começava (alguns professores tinham muito medo de tocar nesses assuntos e tal) aí eu começava a abrir debate. E provocar mesmo os professores pra eles darem a opinião deles e trazer um conhecimento maior pra sala. Mas nunca teve nada separado pra isso.

Parece haver na narrativa de Irene certa perspectiva queer de desestabilização: “provocar mesmo os professores”. Nesse sentido, o que traz Guacira Louro (2004) é feito experiência, queerizar os espaços escolares sugerindo "o questionamento, a desnaturalização e a incerteza como estratégias férteis e criativas para pensar qualquer 
dimensão da existência.” (p. 52). É nesse lugar provocador que se pensa a produção e ampliação dos saberes sobre gênero e sexualidade: "trazer um conhecimento maior pra sala”, construir novos discursos que dizem, também, de suas multiplicidades.

Esses saberes não dirão apenas da não-binaridade de gênero ou de sexualidades divergentes da heteronormatividade, mas podem ter a potência de fazer pensar toda matriz de normas de gêneros estudada por Judith Butler (2003). Quando Irene provoca a turma para pensar além dos tabus, pode haver subjetivação não apenas nela mesma, mas também nas (des)(re)construções das identidades binárias. As performances e regulações das expressões de gênero não estão presentes apenas nas pessoas que têm experiências de diferença. Mas, mesmo as pessoas que se enquadram na norma, na identificação, também terão suas limitações, suas negociações de prazeres. As pessoas estariam imersas nessa matriz, exercendo, atravessando e sendo atravessadas pelos jogos de poder, prazer, estranhamento. A realização individual de performar determinado espectro de gênero pode ser desestabilizada pelas relações sociais provocativas de uma sala de aula: "uma das consequências mais significativas da desconstrução dessa oposição binária reside na possibilidade que abre para que se compreendam e incluam as diferentes formas de masculinidade e feminilidade que se constituem socialmente" (LOURO, 2003, p. 34).

Encontros em uma sala de aula que se fazem experiência - seja para quem narra, para colegas de turma, docentes ou qualquer outro sujeito escolar. Encontros escolares, encontros que fizemos com Irene e Nicholas, encontros das duas pombas desnudas de García Lorca. A multiplicidade da experiência não-binária se expressa: cada conversa, cada pessoa, cada corpo, cada momento poderá ser de (des)subjetivação, um novo repensar a diferença, a identidade, o gênero de si e do outro. São processos de (des)(re)construção contínuos, se reiteram nos cotidianos, nas negociações, nos prazeres e nos desconfortos do chão da escola - e para além dele.

\section{Considerações finais}

E talvez nossa vida ainda seja comandada por um certo número de oposições nas quais não se pode tocar, as quais a instituição e a prática ainda não ousaram atacar; oposições que admitimos como inteiramente dadas: por exemplo, entre o espaço privado e o espaço público, entre o espaço da família e o espaço social, entre o espaço cultural e o espaço útil, entre o espaço do lazer e o espaço do trabalho; todos são ainda movidos por uma secreta sacralização. (FOUCAULT, 2003, p. 413). 
Michel Foucault apontou para o binarismo como uma dimensão construída, também, pela sacralização que cerca nossas relações, identidades e instituições. A considerar que, de acordo também com Nadja Hermann (2014), a oposição binária é uma herança metafísica da ocidentalidade, os binários dentro da escola talvez estejam imbricados com algo sacro, que é produzido e reproduzido cotidianamente. Algumas experiências, entretanto, nos fazem pensar que as relações, os gêneros, as identidades e as diferenças são mais múltiplas e complexas que tal lógica sacralizada.

Pensando que os binarismos se cruzam, de forma a reforçar os locais impostos nas hierarquias, poderiam também que os não-binários se entrecruzam? A desconfiança de todos os aparatos que o binarismo se utiliza é potente para olhar a construção da diferença em relação ao binário. Como indica Kanavillil Rajagopalan (2000, p. 121) a interrogação sem piedade nos leva a desconstrução da oposição de "pares de termos como natureza/cultura, realidade/aparência, causa/efeito, língua/fala, fala/escrita, significante/significado, homem/mulher e por aí vai”".

Por fim, seguimos com terra pela cintura indo ao encontro do sol e da lua, das pombas e das aguiazinhas, e nos colocamos a mesma pergunta de Anne Fausto-Sterling (2006, p. 60): "por que usar dualismos para analisar gramaticalmente o mundo?", quais as consequências, os silenciamentos e as repressões que essa forma de pensar, ser e estar binária, oposicional e hierárquica tem (re)produzido?

\section{Referências}

BENTO, Berenice. A reinvenção do corpo: sexualidade e gênero na experiência transexual. 2 ed. Natal: EDUFRN, 2014.

BENTO, Berenice. O que é transexualidade. São Paulo: Brasiliense, 2008.

BUTLER, Judith. Problemas de gênero: feminismo e subversão da identidade. Rio de Janeiro: Editora Record, 2003.

DEACON, Roger; PARKER, Ben. Educação como sujeição e como recusa. In: SILVA, Tomaz Tadeu. da.(Org.). O sujeito da educação: estudos foucaultianos. 7. ed. Petrópolis, RJ: Vozes, 2010. p. 97-109. 
BERNINI, Lorenzo. Macho e fêmea Deus os criou!? A sabotagem transmodernista do sistema binário sexual. Bagoas-Estudos gays: gêneros e sexualidades. Natal, v. 5, n. 06, 2012.

DERRIDA, Jacques. Posições. Trad. Tomaz Tadeu da Silva. Belo Horizonte: Autêntica, 2001.

DUSCHATZKY, Silvia; SKLIAR, Carlos. O nome dos outros. Narrando a alteridade na cultura e na educação. In: LARROSA, Jorge; SKLIAR, Carlos (Orgs.). Habitantes de Babel: políticas e poéticas da diferença. 2 ed. Belo Horizonte: Autêntica, 2011. p. 119138.

FAUSTO-STERLING, Anne. Cuerpos sexuados: la política de género y laconstrucción de lasexualidad. Barcelona: Melusina, 2006.

FOUCAULT, Michel. Outros espaços. In: Ditos e escritos III - Estética: Literatura e pintura, música e cinema. Rio de Janeiro: Forense Universitária, 2003, p. 411422.

HERMANN, Nadja. A questão do outro e o diálogo. Revista Brasileira de Educação, São Paulo, v. 19, n. 57, p. 477-493, 2014.

LOURO, Guacira Lopes. Gênero, sexualidade e educação: uma perspectiva pósestruturalista. 6 ed. Petrópolis, RJ: Vozes, 2003.

LOURO, Guacira Lopes. Um corpo estranho: ensaios sobre sexualidade e teoria queer. Belo Horizonte: Autêntica, 2004.

LORCA, Federico García. Obra Poética Completa. Trad.: William Agel de Melo. 5 ed. São Paulo: Editora UnB, 2004.

MEYER, Dagmar Estermann; PARAÍSO, Marlucy Alves (Orgs.). Metodologias de pesquisa pós-críticas em educação. Belo Horizonte: Mazza Edições, 2012.

MISKOLCI, Richard. Teoria Queer: um aprendizado pelas diferenças. Belo Horizonte: Autêntica, Ouro Preto: UFOP, 2012.

MISKOLCI, Richard. Estranhando as Ciências Sociais: notas introdutórias sobre Teoria Queer. Florestan, São Carlos, n. 2, p. 08, 2014.

PEDROSO JUNIOR, Neurivaldo Campos. Jacques Derrida e a desconstrução: uma introdução. Revista Encontros de Vista, Recife, v.1, n.5, p. 9-20, 1983.

RAJAGOPALAN, Kanavillil. Ética da Desconstrução. In: NASCIMENTO, Evandro; GLENADEL, Paula (Orgs.). Em Torno de Jacques Derrida. Rio de Janeiro: 7 Letras, 2000. 
RADL-PHILIPP, Rita. Educación y socialización humana, identidades y nuevos roles de género femenino y masculino: el género a debate. Em Aberto. Brasília, v. 27, n. 92, p. 1-212, 2014.

SCOTT, Joan. Gênero: uma categoria útil de análise histórica. Educação \& Realidade, Porto Alegre, v. 20, n. 2, jul./dez. 1995, p. 71-99.

VARELA, Júlia. O Estatuto do Saber Pedagógico. In.: SILVA, Tomaz Tadeu. da.(Org.). O sujeito da educação: estudos foucaultianos. 7 ed. Petrópolis, Rio de Janeiro: Vozes, 2010. p. 97-109. 